\title{
NÚMERO 52
}

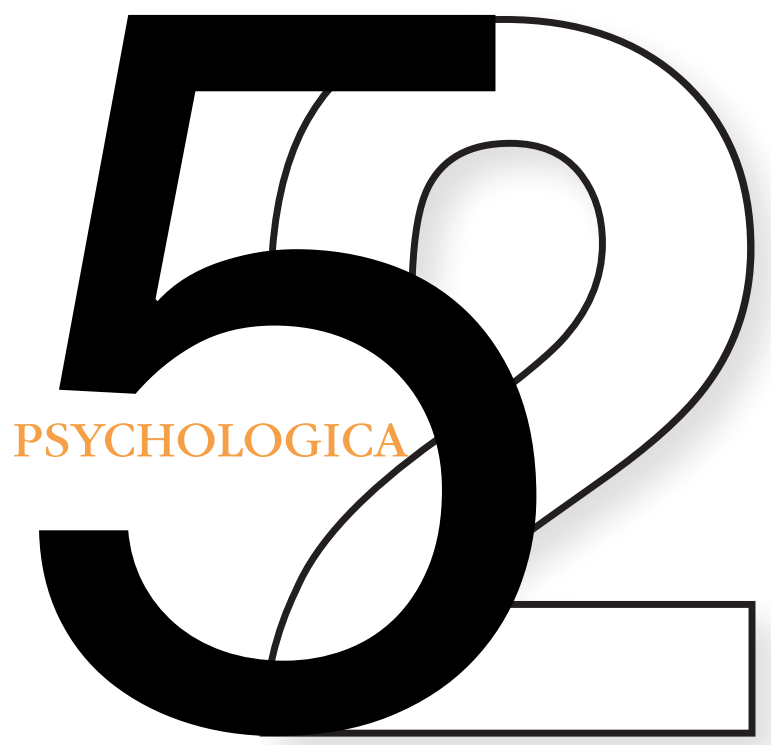

VOLUME I

IMPRENSA DA UNIVERSIDADE DE COIMBRA

FACULDADE DE PSICOLOGIA E DE CIÊNCIAS DA EDUCAÇÃO DA UNIVERSIDADE DE COIMBRA

\section{Versão integral disponível em digitalis.uc.pt}




\title{
A entrevista no estudo da Excelência: Uma proposta
}

\author{
Liliana S. Araújo', José Fernando A. Cruz² \& Leandro S. Almeida
}

\begin{abstract}
A investigação em torno da Excelência Humana tem primado pela multiplicidade de abordagens teóricas e metodológicas ao seu estudo. Por um lado, o próprio conceito de excelência encerra a dificuldade da sua operacionalização, reflectindo-se numa multiplicidade de critérios de identificação e de métodos de investigação. Por outro lado, a singularidade subjacente ao próprio conceito de excelência alimenta a discussão em torno das metodologias mais adequadas ao seu estudo. As abordagens quantitativas reclamam o estudo objectivo e laboratorial do desempenho excepcional, embora se questione o significado de resultados generalizáveis e quantificáveis sobre desempenhos singulares ou individuais. Neste sentido, a investigação poderá beneficiar de uma abordagem mais aprofundada e compreensiva dos percursos de excelência proporcionada pelas metodologias qualitativas. Outros autores defendem ainda o recurso a metodologias mistas procurando vencer limitações e ampliar potencialidades no estudo da excelência. Estudos recentes com indivíduos excepcionais têm utilizado a entrevista como um instrumento privilegiado de recolha de dados. Neste artigo apresentamos uma revisão de literatura onde foram analisadas as principais características de entrevistas utilizadas no estudo da excelência em diferentes contextos de realização. Como corolário desta revisão apresentamos uma proposta de guião de entrevista procurando, assim, contribuir para o estudo do desenvolvimento e manutenção da excelência.
\end{abstract}

PALAVRAS-CHAVE: Entrevista, Excelência, Metodologia qualitativa, Desporto, Ciência, Dança.

\section{Introdução}

Frequentemente grande parte da investigação psicológica privilegia o uso de metodologias quantitativas na recolha e análise de dados. Mesmo quando se recorre a algum tipo de análise qualitativa, esta é geralmente pensada como complementar ou codificada de forma a traduzir-se em dados quantificáveis. Aliás, como refere Simonton (2003), qualquer estudo empírico típico baseado nas

\footnotetext{
1 Centro de Competência de Alter e Humanidades, Universidade da Madeira - Igsaraujo@gmail.com 2 Escola de Psicologia, Universidade do Minho - jcruz@psi.uminho.pt 3 Instituto de Educação, Universidade do Minho - leandro@ie.uminho.pt
} 
normas da APA (American Psychological Association) partilha duas características principais: a) os dados são inerentemente quantitativos, e b) não têm qualquer valor intrínseco, valendo apenas como meios para atingir um objectivo: testing of nomothetic hypotheses about human thought, affect, or behavior (p. 618).

254 Contudo, ao longo da história da Psicologia encontramos trabalhos de referência sobre o estudo de indivíduos excepcionais que recorreram essencialmente a dados descritivos (históricos, biográficos, estudos de caso), imprimindo uma dimensão qualitativa na investigação psicológica em excelência. A título de exemplo, refirase o célebre livro Hereditary Genius de Francis Galton sobre a vida de cientistas eminentes em 1869, os estudos de Anne Roe com cientistas e artistas (1946/1951), ou o estudo de Bloom com jovens talentosos em várias áreas publicado em 1985. Mais recentemente, o interesse pelo estudo das vidas e obras de cientistas, artistas, atletas e outras personalidades eminentes revela-se em trabalhos como o de Gardner em Creating Minds (1993) e em inúmeros trabalhos em contextos mais específicos como os recentes trabalhos de Gould e seus colaboradores no domínio do desporto de alta competição (ver Gould, Collins, Lauer, \& Chung, 2007; Gould, Dieffenbach, \& Moffett, 2002).

Por outro lado, o advento do movimento da Psicologia Positiva impulsionou na investigação psicológica uma maior preocupação com as forças humanas, pelos traços positivos individuais e as experiências subjectivas positivas (Snyder \& Lopez, 2002). Neste sentido, presenciamos um crescente interesse por temas como os talentos, a sabedoria, a liderança e a criatividade, ou seja, assiste-se a uma nova ênfase nas qualidades positivas dos indivíduos, como o bem-estar e o optimismo, que permitem lidar mais eficazmente com as adversidades. O estudo da excelência humana enquadra-se nesta inquietação dos investigadores em compreender e explicar os desempenhos excepcionais de determinados indivíduos. Assim, as metodologias qualitativas primam por permitirem aos investigadores um conhecimento aprofundado e compreensivo do desenvolvimento de um percurso de excelência através dos construtos, experiências e significados do próprio indivíduo. Como refere Kvale (1996), "a entrevista de investigação qualitativa tenta compreender o mundo do ponto de vista do sujeito, para revelar o significado das experiências das pessoas, para descobrir o seu mundo vivido, antes de explicações científicas" (p. 1). Neste sentido, a recolha de dados descritivos através de metodologias essencialmente qualitativas parece ser, assim, fundamental para o desenvolvimento posterior de conceptualizações teóricas mais refinadas e compreensivas (Poczwardowski \& Conroy, 2002).

A entrevista surge, então, como método dominante de recolha de dados desta natureza. De acordo com Creswell (2003), as entrevistas qualitativas permitem explorar tópicos relativamente pouco explorados, identificar padrões e temas sob a 